\title{
EPINEPHRIN REACTION IN OBESITY
}

\author{
By CLEMENT I. KRANTZ AND JAMES H. MEANS
}

(From the Metabolism Laboratory of the Massachusetts General Hospital, Boston, Massachusetts)

(Received for publication August 6, 1926)

That a departure from the usual in metabolism, either qualitative or quantitative must exist in obesity seems self evident. In many instances, of course, the direction of this departure is plain and lies in a food intake obviously excessive. In other cases the nature of the metabolic fault is obscure.

Aside from excessive food intake, the fundamental cause of obesity conceivably may lie in a depressed rate of basal metabolism or in a lowered metabolic response to any of the calorigenetic stimuli that affect the human body. Studies of the basal metabolic rate in obesity have been made in this laboratory and several reports published (1). No consistent variation from normal has been found. Confirmatory evidence has been reported by Boothby and Sandiford from the Mayo Clinic (2). More recently Strouse and his co-workers have made studies in the specific dynamic action of various food substances and find that the specific dynamic action of protein is lowered in the socalled constitutional obesity (3). A similar finding has been reported by Plaut (4), but denied by Lauter (5), who states that "in the varied types of obesity, the specific dynamic action of protein often gave very high values and on the whole they were not lowered." He ascribes the origin of obesity to the food intake which is more than suffcient for the energy needs and a deposition of fat then results.

It is well known that thin persons are often nervous and emotional, and fat ones seldom so. For this reason, in the further search for a metabolic fault, it seemed advisable to study the physiological metabolic response to emotion in the obese. Since we could provide no standardizable psychic stimulus, and since in view of Cannon's work (6) it is reasonable to assume that any psychic stimulus affects 


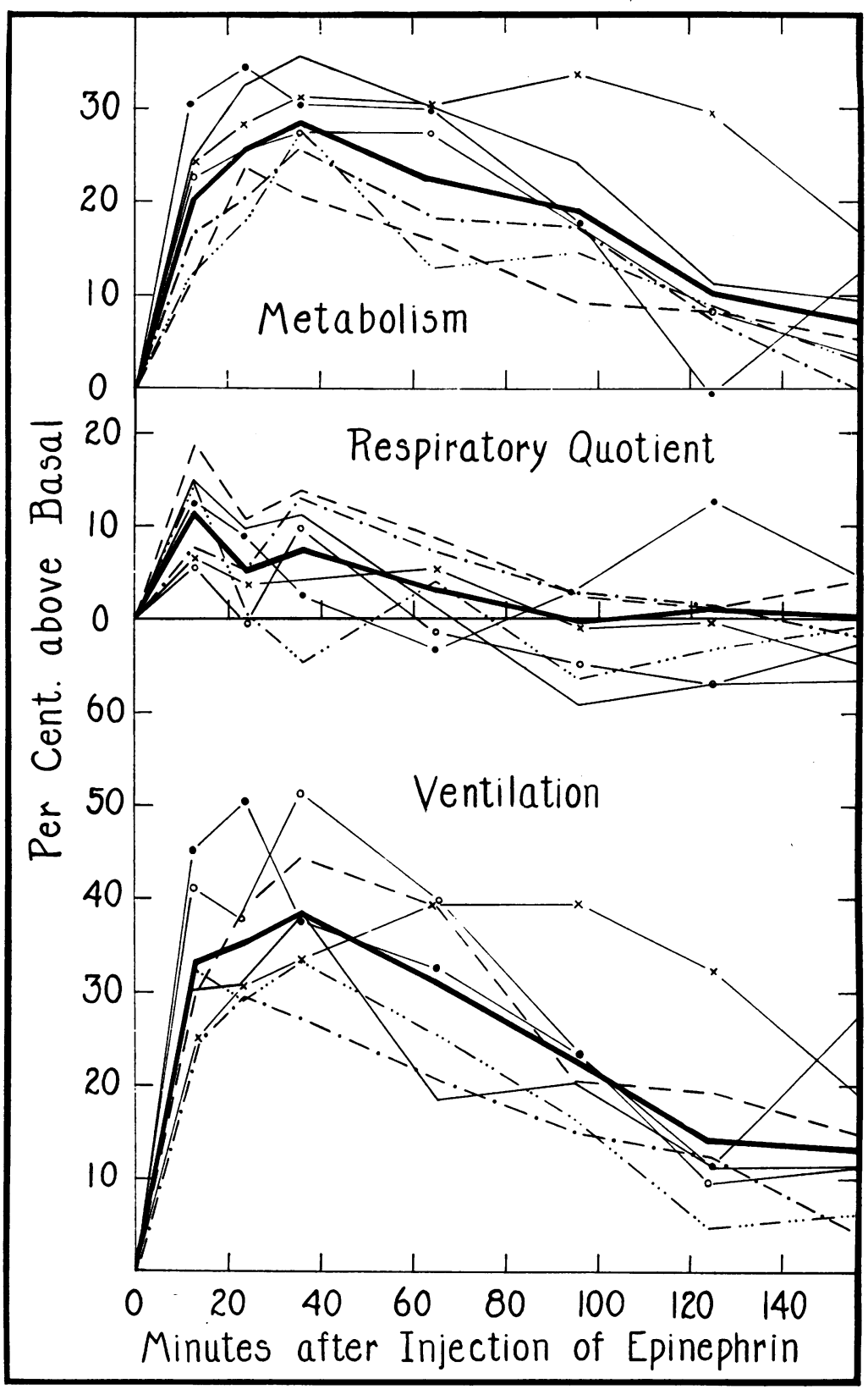

Fig. 1. Metabolic Rate, Respiratory Quotient and Ventilation after EPINEPHRIN INJECTION IN SEVEN OBESE SubJects

The heavy lines are the composite curves for the group, the thin lines those for the individual subjects. Each type of line denotes a particular subject throughout.

Results are all expressed as per cent above or below the basal readings, that is to say all curves start at 0 , which is the basal before the drug was given, so as to make the curves comparable. 


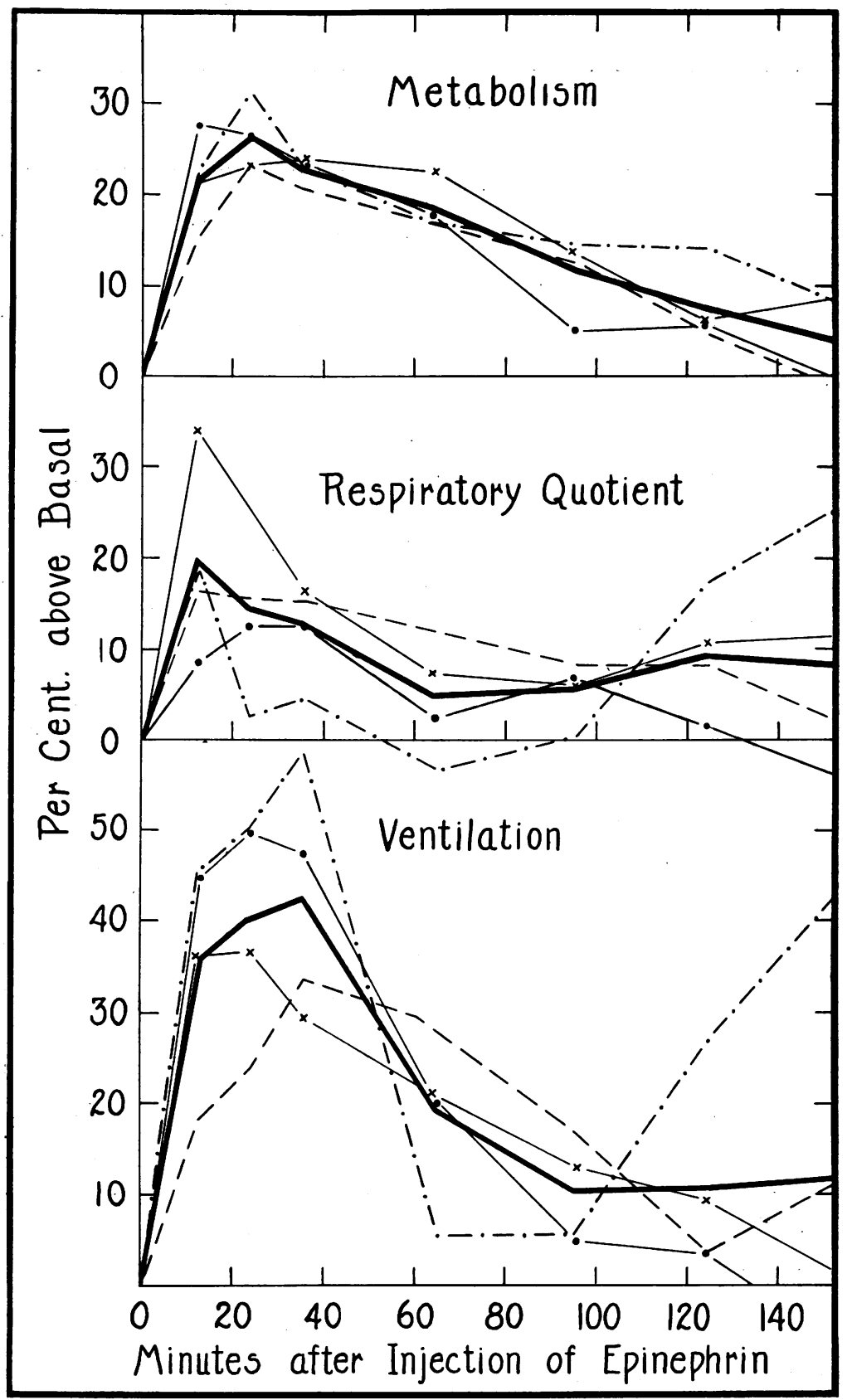

Fig. 2. Metabolic Rate, Respiratory Quotient and Ventilation after EPINEPhRIN IN THE NORMal SUbJECTS 
metabolism through its effect on epinephrin secretion, we decided to attack our problem by observing the metabolic response to the direct

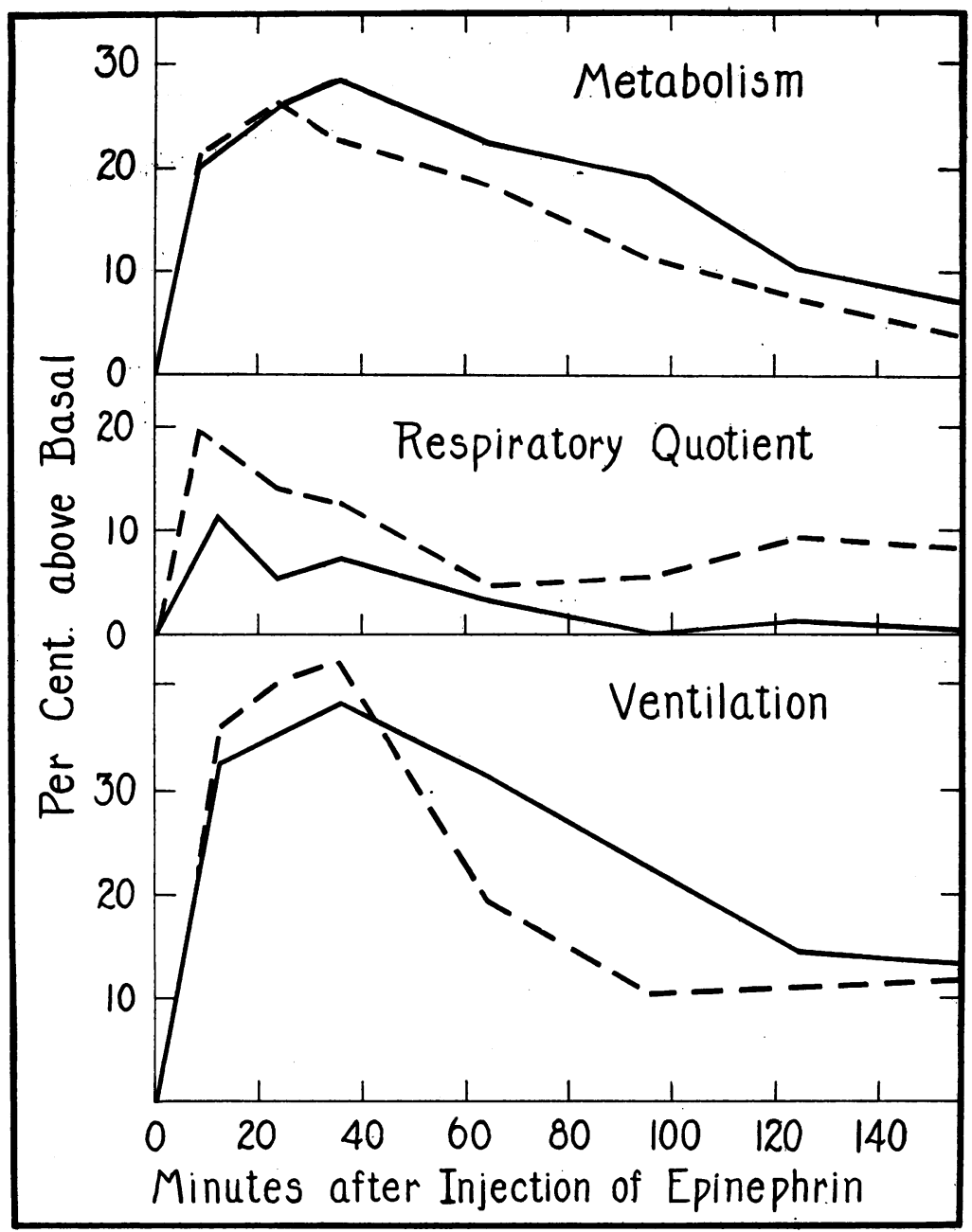

Fig. 3. .Composite Curves from Figures 1 and 2 Shown Together

Heavy lines show obese and dotted lines normal subject curves

injection of epinephrin. Tompkins, Sturgis and Wearn (7) have reported the effects of epinephrin injection on basal metabolism in 
cases with "irritable heart" and Sandiford (8) has studied its effect on heat production, blood pressure and pulse rate in man. The

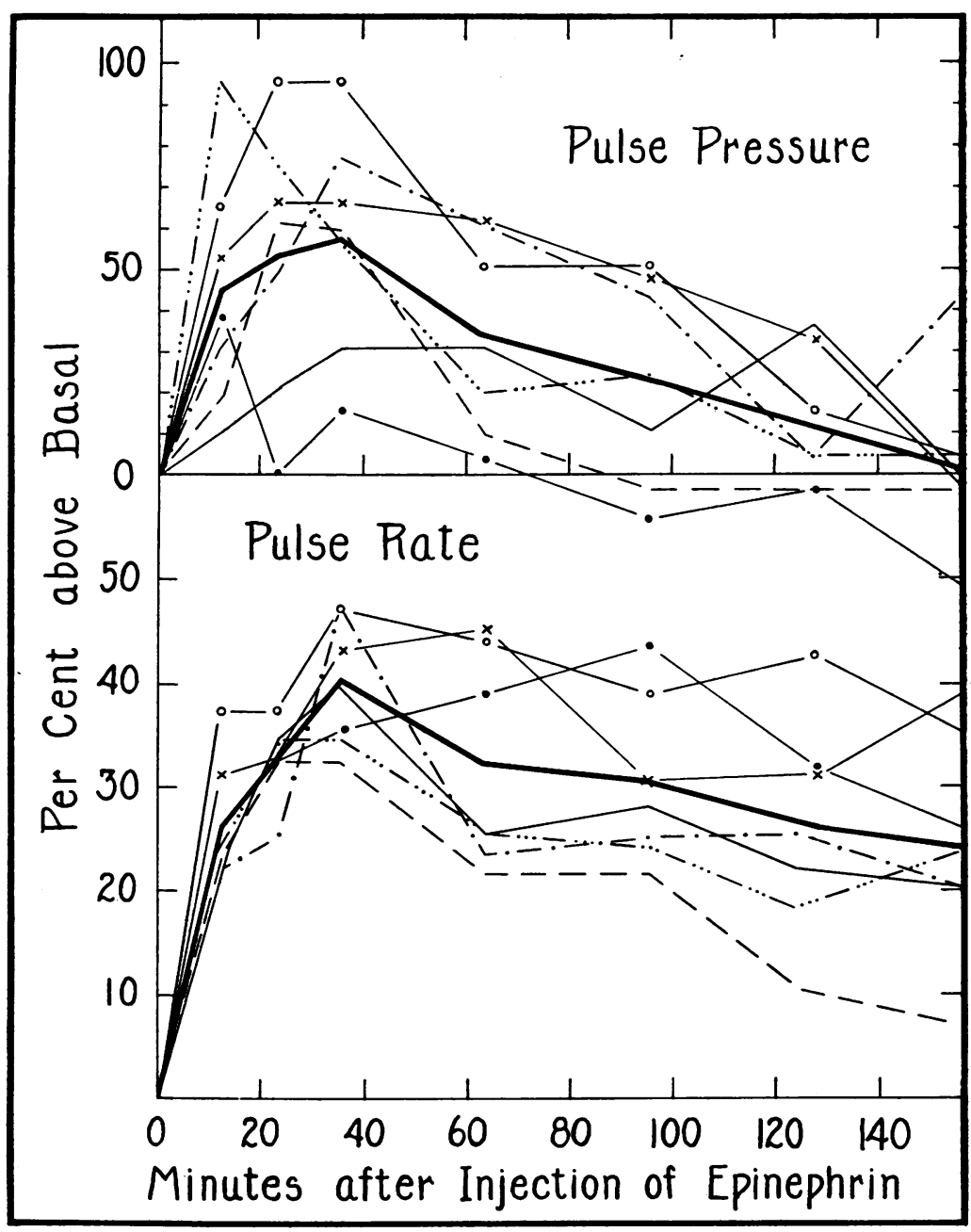

Fig. 4. Pulse Pressure and Pulse Rate for the Experiments Shown in Figure 1, Obese Series

present report gives the result of such a study in a series of obese patients. In addition to the metabolic rate itself, we have likewise 
observed the changes in respiratory quotient, pulmonary ventilation, pulse rate and blood pressure. The obese persons studied were free

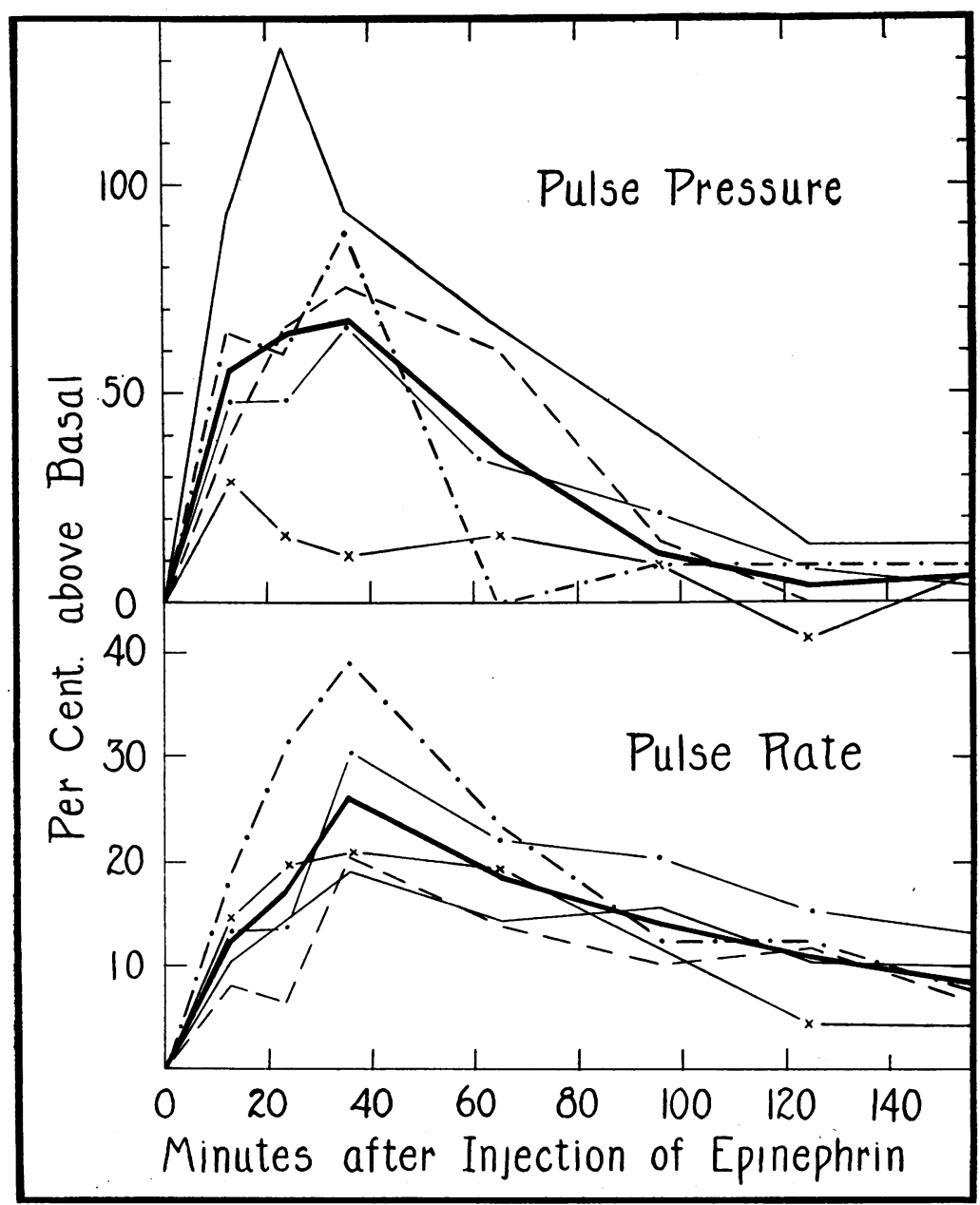

Fig. 5. Pulse Pressure and Pulse Rate for the Experiments Shown in Figure 2, Normal Series

from apparent endocrine disturbance and belonged to the type that may be called simple obesity. 


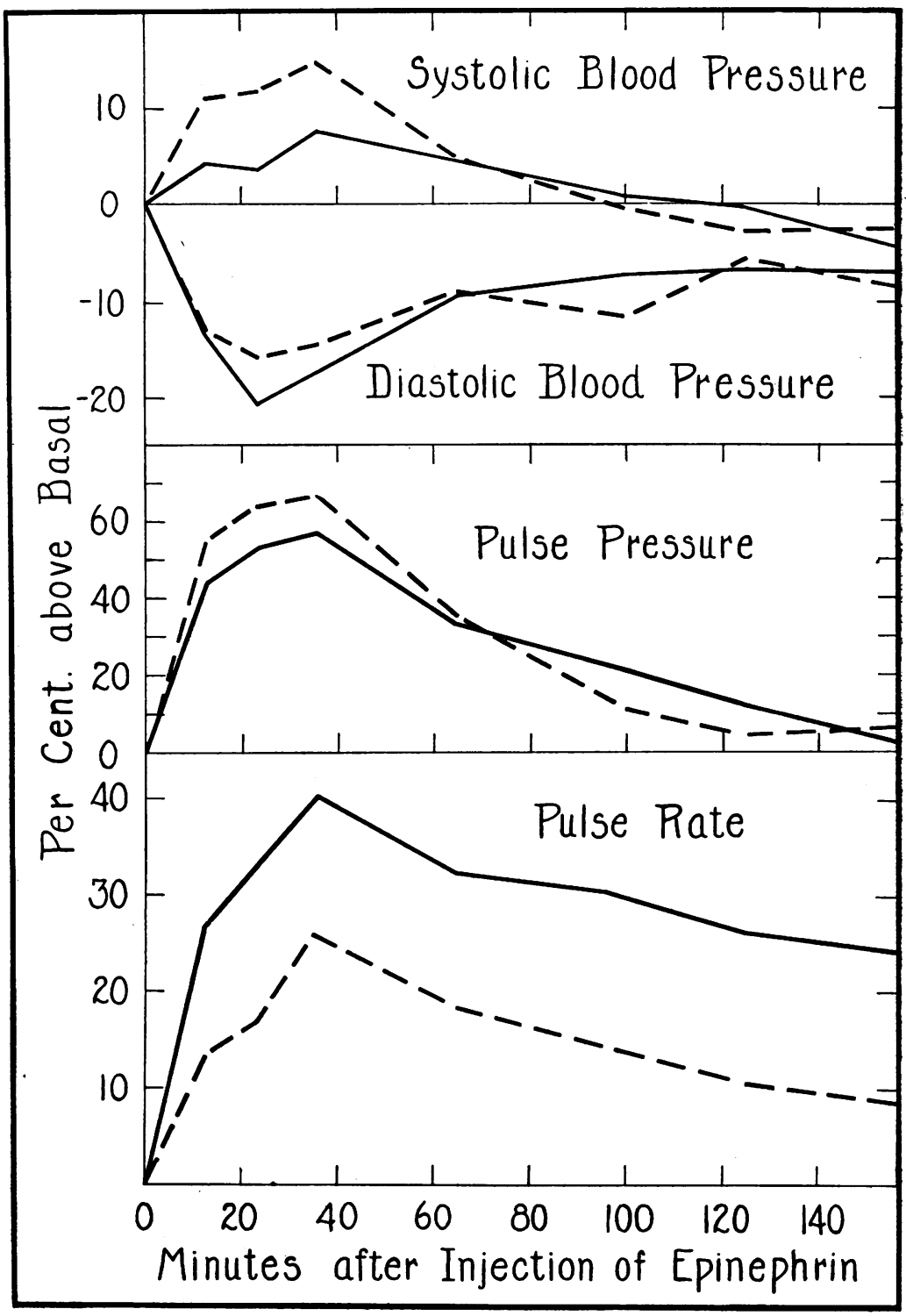

Fig. 6. Composite Curves of Systolic and Diastolic Blood Pressures, Pulse Pressure and Pulse Rate for Both Sertes

Heavy line $=$ obese; dotted line $=$ normal 


\section{METHODS}

The patients were all studied in the post absorptive condition, twelve hours or more after the last meal. On arriving at the laboratory the patient was given a preliminary rest period of 30 minutes before any determinations were made. Then two metabolism readings were made and the lower of the two was taken as the basal. Blood pressure and pulse rate readings were taken at the same time. Epinephrin was then injected into the arm of each individual and readings started at $10,20,30,60,90,120$ and 150 minutes after injection. The patients remained in the resting condition throughout the experiment.

The metabolic studies were all made on a Tissot gasometer, from which duplicate samples of expired air were withdrawn and analyzed for oxygen and carbon dioxide by the usual Haldane gas analysis apparatus. Expired air was collected over a period of 10 minutes in each case, except for the two periods, 10 and 20 minutes after epinephrin injection, when 6 minute periods were taken, because of the rapidity of change after giving the drug. The ventilation, basal metabolism and respiratory quotients were thus obtained from the readings on the gasometer and analyses on the Haldane apparatus. Blood pressures were measured by a mercury sphygmomanometer.

The tablet form of epinephrin (Adrenalin; Parke, Davis and Company) was used in each instance, because of the tendency of epinephrin solution to deteriorate on standing. Each tablet contained $\frac{1}{2} 0$ grain epinephrin and for injection two tablets were mixed with a minimum of water, each patient receiving therefore $0.625 \mathrm{mgm}$. of epinephrin.

\section{RESULTS}

The reactions to epinephrin obtained both in our obese patients and in normal individuals are shown graphically in figures 1 to 6 . To facilitate comparison, all values are expressed in per cent above or below the basal level. Individual and composite curves are given for each group. The basal values for all factors are shown in tables 1 and 2. In the charts it will be noted that each reading is not placed 10,20 or 30 minutes after the epinephrin injection, but a little later in each case. The individual tests were all started at these intervals, 
but in order to account for the time needed for making the test, a point midway between the beginning and end of the period was

TABLE 1

Obese subjects

\begin{tabular}{l|c|c|c|c|c|c|c|c|c}
\hline Name & Age & Height & Weight & $\begin{array}{c}\text { Over } \\
\text { weight }\end{array}$ & $\begin{array}{c}\text { Basal } \\
\text { ventila- } \\
\text { tion }\end{array}$ & $\begin{array}{c}\text { Basal. } \\
\text { R.Q. }\end{array}$ & $\begin{array}{c}\text { Basal } \\
\text { metabo- } \\
\text { lism }\end{array}$ & $\begin{array}{c}\text { Basal } \\
\text { pulse }\end{array}$ & $\begin{array}{c}\text { Basal } \\
\text { blood } \\
\text { pressure }\end{array}$ \\
\hline & & $c m$. & kgm. & per cent* & $\begin{array}{c}\text { liters } \\
\text { per hourt }\end{array}$ & & per cent & & \\
N. C. & 28 & 157 & 81 & 45 & 395 & 0.79 & 0 & 63 & $114 / 78$ \\
L. V. & 28 & 170 & 107 & 66 & 385 & 0.72 & -4 & 55 & $110 / 68$ \\
H. C. & 18 & 159 & 103 & 92 & 374 & 0.78 & -4 & 79 & $124 / 82$ \\
P. & 38 & 154 & 106 & 81 & 456 & 0.79 & $+26 \ddagger$ & 64 & $150 / 96$ \\
R. & 37 & 156 & 109 & 89 & 351 & 0.72 & +5 & 63 & $120 / 82$ \\
D. A. & 26 & 165 & 114 & 92 & 448 & 0.81 & +5 & 66 & $122 / 80$ \\
R. P. & 38 & 162 & 88 & 43 & 337 & 0.75 & -9 & 59 & $116 / 78$ \\
\hline
\end{tabular}

* These figures were calculated from the Tables of Association of Life Insurance Directors and Actuarial Soc. of America, New York, 1912, p. 38.

$\dagger$ The basal ventilation is expressed in liters per hour, uncorrected for barometer and temperature.

$\ddagger$ This patient showed a slightly elevated metabolism on several occasions, a cause for which was not discovered. She showed no evidence of hyperthyroidism. She had been on an obesity diet for several months and was losing weight satisfactorily.

TABLE 2*

Normal subjects

\begin{tabular}{|c|c|c|c|c|c|c|c|c|}
\hline Name & Age & Height & Weight & $\begin{array}{c}\text { Basal } \\
\text { ventila- } \\
\text { tion }\end{array}$ & $\begin{array}{l}\text { Basal } \\
\text { R.Q. }\end{array}$ & $\begin{array}{c}\text { Basal } \\
\text { metabo- } \\
\text { lism }\end{array}$ & $\begin{array}{l}\text { Basal } \\
\text { pulse }\end{array}$ & $\begin{array}{c}\text { Basal } \\
\text { blood } \\
\text { pressure }\end{array}$ \\
\hline & & $\mathrm{cm}$. & kgm. & per cent & & per cent & & \\
\hline J. G. & 38 & 167 & 73 & 287 & 0.77 & -11 & 64 & $98 / 64$ \\
\hline J. C. & 45 & 169 & 63 & 461 & 0.80 & -5 & 87 & $118 / 78$ \\
\hline W. B. $\dagger$ & 64 & 164 & 54 & 347 & 0.76 & -19 & 67 & $118 / 56$ \\
\hline H. H. & 19 & 159 & 50 & 320 & 0.81 & -9 & 63 & $108 / 64$ \\
\hline G. C. $\ddagger$ & 20 & 164 & 46 & & & & 69 & $108 / 78$ \\
\hline
\end{tabular}

* Footnotes * and $\dagger$ of table 1 apply also to table 2 .

$\dagger$ W. B. had recently recovered from lobar pneumonia accounting for his low basal metabolism.

$\ddagger$ Metabolic studies were not completed on patient G. C.

taken as the average. Thus the readings of the 10 and 20 minute periods have been charted as at 13 and 23 minutes, while the remaining periods are all charted 5 minutes after the test was started. Figures 
1 and 4 show the results in the obese subjects, figures 2 and 5 in the normal controls and figures 3 and 6 represent a composite picture of all results for comparison.

The only striking and constant differences between the obese and normal group were in the behavior of the respiratory quotient and in that of the pulse rate.

Metabolism. The heat production in the two groups was not significantly different. In the obese an average metabolism of 28.3 per cent above basal was reached in 30 minutes, while a height of 26.1 per cent was reached in the normal controls. The heat production had not quite returned to its basal level at the end of two and onehalf hours.

Ventilation. The rate of ventilation was calculated on the hourly basis and showed an abrupt rise after epinephrin, the highest level being reached in both normal and obese subjects 30 minutes after injection. These figures showed no significant variation from one another, the average reaching 38.1 per cent above basal in the obese subjects and 42.2 per cent in the normals. The control curves showed greater individual variations than the obese and the drop to a lower level was a little more rapid in the composite control curve. It will be noticed that the relative increase in ventilation was greater in both groups than that in the metabolism.

Pulse rate. The pulse rate rose more rapidly and to a greater height in the obese. It is of interest to note that the average basal pulse in the obese was 65 while it was 70 in the controls. The highest level in each case was reached in 30 minutes after injection, reaching 40 per cent above basal in the obese and 26 per cent in the normal individuals. In no case did the pulse rates reach the basal level, but stayed up higher in the obese throughout the duration of the experiments.

Pulse pressure. The pulse pressures showed wide individual variations in both groups of cases. In one obese case the pulse pressure dropped considerably below the normal level. However the average pulse pressures showed no significant variation from one another.

The average systolic pressure rose more in the normal than in the obese, reaching.11.2 per cent above basal in the former and only 4.2 per cent in the latter in 10 minutes, while at the end of the 30 minute period it had reached 14.3 per cent and 7.7 per cent in each respectively. 
The diastolic levels showed no marked variations. The systolic and diastolic blood pressure variations are recorded in figure 6 and show no great variation from one another.

Respiratory quotient. The respiratory quotients reached their highest level in 10 minutes after injection, somewhat sooner than the other factors. The average rise in quotient in the normal subjects reached a level of 19.6 per cent above the basal, while in the obese subjects 11.2 per cent above basal was the highest figure reached. The composite curve for the obese is consistently lower than that of the normals during the entire experimental period and the individual curves more often go below the basal quotient than not.

The significance of this altered behavior of the respiratory quotient after epinephrin in obesity is not entirely clear. It indicates that the increase in metabolism is met by a relatively greater oxidation of fat and less of carbohydrate than in normal persons. The respiratory rate increased proportionately and equally in both the obese and normals. Whether this difference in quotients throws any light on the fundamental nature of obesity cannot be told at present.

The interpretation of the respiratory quotients in terms of percentages of food stuffs burned cannot be made with certainty at present. The literature gives conflicting data on the effect of epinephrin on the protein metabolism and work is now in progress in this laboratory to determine this effect. The most convincing paper is by Allan et al. (9), who believe that epinephrin has a decided effect on protein metabolism.

\section{CONCLUSIONS}

1. The characteristic increase in total metabolism, pulmonary ventilation, and pulse pressure following epinephrin injection was found to be not of a significantly different magnitude in the obese than in persons of normal weight.

2. The respiratory quotient, on the other hand, seemed to rise definitely less in obese persons than in normal persons after epinephrin.

3. The pulse showed more acceleration in the obese than in normal persons. 


\section{BIBLIOGRAPHY}

1. Means, J. H.: Jour. Med. Res., 1915, xxvii, 121. Studies of the Basal Metabolism in Obesity and Pituitary Disease.

Means, J. H.: Arch. Int. Med., 1916, xvii, 704. The Basal Metabolism in Obesity.

2. Boothby, W., and Sandiford, I.: Jour. Biol. Chem., 1922, liv, 783. Summary of the Basal Metabolism Data on 8614 Subjects with Especial Reference to the Normal Standards for the Estimation of the Basal Metabolic Rate.

3. Wang, C. C., and Strouse, S.: Arch. Int. Med., 1924, xxxiv, 573. Studies on the Metabolism of Obesity. III. The Specific Dynamic Action of Food.

4. Plaut, R.: Deutsch. Arch. f. klin. Med., 1922, cxxxix, 285. Gaswechseluntersuchungen bei Fettsucht und Hypophysiserkrankungen.

5. Lauter, S.: Deutsch. Arch. f. klin. Med., 1926, cl, 315. Zur Genese der Fettsucht.

6. Cannon, W. B.: Bodily Changes in Pain, Hunger, Fear and Rage. D. Appleton \& Co., New York, 1915.

7. Tompkins, E. H., Sturgis, C. C., and Wearn, J. T.: Arch. Int. Med., 1919, xxiv, 269. Studies on Epinephrin. II. Effects of Epinephrin on the Basal Metabolism in Soldiers with "Irritable Heart," in Hyperthyroidism and in Normal Men.

8. Sandiford, I.: Amer. Jour. Phys., 1920, li, 407. The Effect of the Subcutaneous Injection of Adrenalin Chlorid on the Heat Production, Blood Pressure and Pulse Rate in Man.

9. Allan, F. N., Dickson, B. R., and Markovitz, J.: Amer. Jour. Phys., 1924, lxx, 333. The Relationship of Phosphate and Carbohydrate Metabolism. II. The Effect of Adrenalin and Phloridzin on the Excretion of Phosphate. 